\title{
Feasibility Analysis of Virtualization Scheme for Distributed Combat Systems
}

\author{
[Jin-Yong Im, Sung-Hun Kim, and Dong-Seong Kim* ]
}

\begin{abstract}
This paper investigates an overall performance of virtualization schemes for a distributed combat system. The analyzed results can be used to enhance design approach for a naval combat system virtualization environment. An integrated ship computing environment for distributed combat systems needs a seamless operation environment. In such a case, hardware resource is constructed considering over load when naval combat system is constituted. Virtualization environment construction is tried for solving problems such as assets overinvestments, etc. However, previous researches focus on virtualization structure research, without what is a suitable virtualization scheme for naval combat systems. Therefore, this paper evaluates available functions and performance through message transmission in a Data Distributed Service (DDS) environment. Experimental results show that performance of each virtualization scheme messages response time.
\end{abstract}

Keywords-Distributed Combat Systems, Naval Combat System, Integrated Ship Computing Environment, Virtualization, Data Distribution Service.

\section{Introduction}

Recently, many war ships use many clients and servers due to the development of naval combat systems. The large number of clients and servers can lead to the discomfort of management, waste power and hardware resources. Naval combat systems needs a non-stop operating environment because of the system's uniqueness. For this purpose, naval combat systems are constructed depending on battle time[13]. The virtualization environments of next generation naval combat systems are researched to solve these problems through using physical hardware to logical ways. For that, the important thing is the selection of virtualization schemes, which is suitable for a naval combat system virtualization environment. Fig. 1 shows classification of virtualization technologies. For the selection of a virtualization scheme, we need to research on a variety of areas for the next generation naval combat system. This paper analyzes available functions and evaluates message transmission performance on DDS environment using four kinds of major virtualization schemes, such as VMware, Hyper_V, Xen and KVM. An analysis of available functions

Jin-Yong Im

Kumoh National Institute of Technology

Republic of Korea

Sung-Hun Kim

Cheongshim International Academy

Republic of Korea

Dong-Seong Kim*

Kumoh National Institute of Technology

Republic of Korea

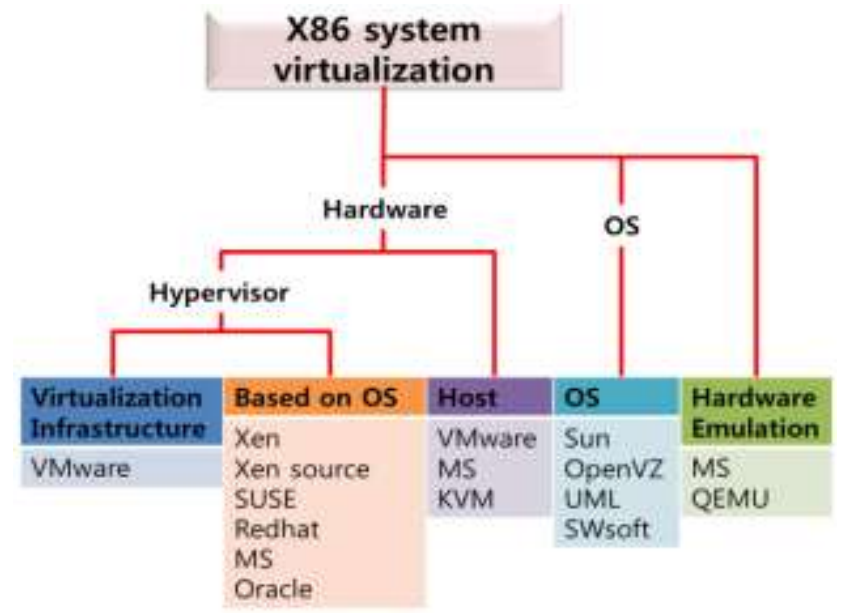

Figure 1. Classification of Virtualization Technologies. and experimental results show the strength area and characteristic of each virtualization scheme.

In Section II, we will explain about the requirements included within naval combat system virtualization environments. Section III shows available functions from each virtualization scheme. Section IV shows performance evaluation of message transmission on DDS. Section V discusses conclusions.

\section{Integrated Ship Computing Environment}

Naval combat systems is configured by lower systems that consider missions of war ship. Lower systems are unit systems consisting of equipment such as servers, storage devices, terminals, sensors and weapons. And it contains system based software and operating system based middleware. Lower systems of the computing systems are linked with each other for exchanging data processed by each servers [4].

Limitations of naval combat systems are two significant

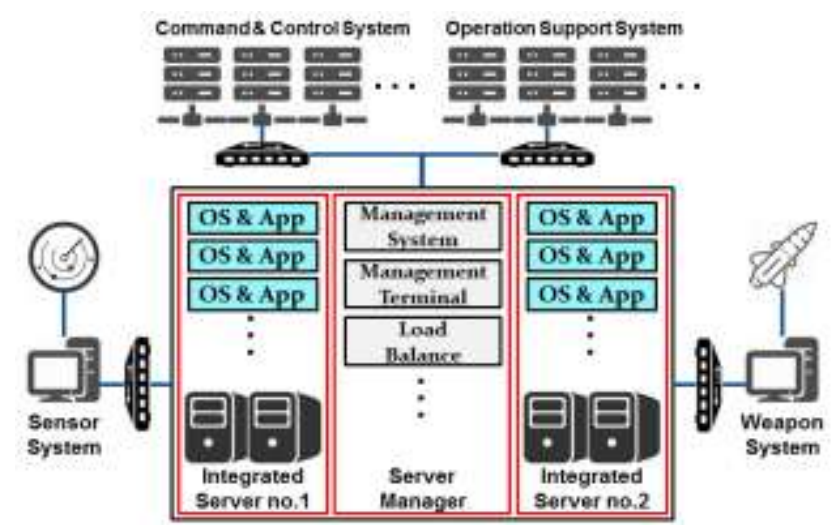

Figure 2. Model of Integrated Ship Computing Environment. 


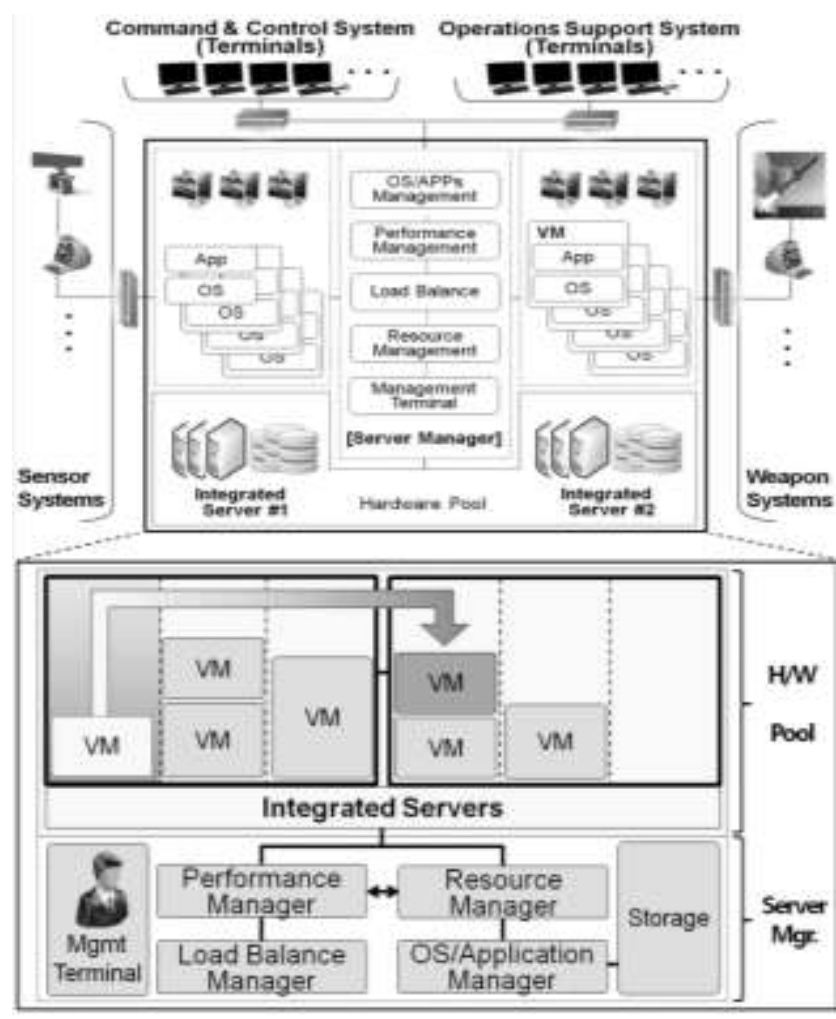

Figure 3. Virtualization Model of Naval Combat Systems [2].

things. First, a consideration of the computing resource for data processing and integrated operation of server in lower systems are insufficient. Second, the efficient usage of operating device and computing resource are limited. Command and control systems operate on commercial desktop and its main function is web service. Computing resources are used on each devices such as CPU and storage, cannot use from other devices. For overcoming limited resource and transplantation of application in naval combat systems, integrated of servers based on virtualization and VDI (Virtual Desktop Infrastructure) technologies are needed for efficient management of computing resources. In virtualization environment computing resource should be used common hardware resource to each system through remove physical segment in server which is configured integrated server and provides operating system and application to virtual machine.

A zero client should be applied to naval combat systems through construction of VDI. Operating console should be minimal included monitor and peripherals through integrating of computing resource from individual desktops to server and providing virtual desktop using server. Fig. 3 shows virtualization model for naval combat system is proposed using VDI technology. This model is constructed to integrated server and server manager.

And target tracking system, which is important requirement of naval combat system, continuously shows over than 4,000 targets on console within 1 second. For that, the performance of overall system, such as CPU, Memory and Network, should be same or higher than existing multifunction console.

In case of redundancy, when operating device becomes unavailable, waiting device processes restructuring strategies within 1 second for maintain performance of naval combat system. And virtual machine has to provide the load balancing for processing the task from other virtual machine has overload.

\section{Analysis of Available Functions}

In this section we will analysis the available functions from each virtualization schemes. There are many kind of virtualization hypervisor, however we analyze only 4 major virtualization schemes [5-8]. First one is available functions of expandability on Table I. The mean of numbers are that hypervisor can allocate memory, CPU and NIC to one virtual machine. VMware shows best performance on expandability area generally, despite Hyper_V shows best performance on VM NIC (Virtual Machine Network Interface Card) specially.

TABLE I. AVAILABLE FUNCTIONS OF EXPANDABILITY

\begin{tabular}{|c|c|c|c|c|}
\hline Function & VMware & Hyper_V & Xen & KVM \\
\hline VM Memory & $255 \mathrm{~GB}$ & $64 \mathrm{~GB}$ & $32 \mathrm{~GB}$ & $\begin{array}{c}256 \\
\mathrm{~GB}\end{array}$ \\
\hline VM CPU & 8 & 4 & 8 & 16 \\
\hline VM NIC & 10 & 12 & 7 & 8 \\
\hline $\begin{array}{c}\text { Hypervisor } \\
\text { CPU }\end{array}$ & 128 & 64 & 64 & 128 \\
\hline $\begin{array}{c}\text { Hypervisor } \\
\text { Memory }\end{array}$ & $1 \mathrm{~TB}$ & $1 \mathrm{~TB}$ & $256 \mathrm{~GB}$ & $1 \mathrm{~TB}$ \\
\hline Guest OS & Over than 65 & 25 & 17 & 5 \\
\hline
\end{tabular}

TABLE II. AVAILABLE FunCTIONS OF FLEXIBILITY

\begin{tabular}{|c|c|c|c|c|}
\hline Function & VMware & Hyper_V & Xen & KVM \\
\hline $\begin{array}{c}\text { Online } \\
\text { CPU/Memory } \\
\text { Extension }\end{array}$ & 0 & $X$ & $X$ & $X$ \\
\hline $\begin{array}{c}\text { Online Server } \\
\text { Migration } \\
\text { (vMotion) }\end{array}$ & 0 & 0 & 0 & 0 \\
\hline $\begin{array}{c}\text { Online Storage } \\
\text { Migration } \\
\text { (Storage } \\
\text { vMotion) }\end{array}$ & 0 & $X$ & $X$ & $X$ \\
\hline $\begin{array}{c}\text { DRS(Distributed } \\
\text { Resource } \\
\text { Scheduler) }\end{array}$ & 0 & $\mathrm{X}$ & $\Delta$ & $\Delta$ \\
\hline $\begin{array}{c}\text { HA(High } \\
\text { Availability) }\end{array}$ & $\mathrm{O}$ & $\mathrm{O}$ & $\mathrm{X}$ & $\mathrm{X}$ \\
\hline $\begin{array}{c}\text { Non-stop } \\
\text { Service(Fault } \\
\text { Tolerance) }\end{array}$ & $\mathrm{O}$ & $\mathrm{X}$ & $\mathrm{X}$ & $\mathrm{X}$ \\
\hline
\end{tabular}

Table II shows available functions of flexibility. Four kind of schemes provide online server migration and HA. However only VMware can serve other functions such as online CPU/memory extension, non-stop service and etc. The mean of $\Delta$ is scheme can serve that function partially.

Available functions of network are shown on Table III. Virtual LAN (VLAN) is provided by every scheme. But other available functions are provided by only VMware. In case of Network I/O Control, it is important function for detecting and managing node in naval combat system virtualization environment. 
TABLE III. AVAILABLE FunCtions OF NETWORK

\begin{tabular}{|c|c|c|c|c|}
\hline Function & VMware & Hyper_V & Xen & KVM \\
\hline VLAN & $\mathrm{O}$ & $\mathrm{O}$ & $\mathrm{O}$ & $\mathrm{O}$ \\
\hline $\begin{array}{c}\text { PVLAN(Private } \\
\text { VLAN) }\end{array}$ & $\mathrm{O}$ & $\mathrm{X}$ & $\mathrm{X}$ & $\mathrm{X}$ \\
\hline $\begin{array}{c}\text { Network Security } \\
\text { based on L2 }\end{array}$ & $\mathrm{O}$ & $\mathrm{X}$ & $\mathrm{X}$ & $\mathrm{X}$ \\
\hline $\begin{array}{c}\text { Network I/0 } \\
\text { Control }\end{array}$ & $\mathrm{O}$ & $\mathrm{X}$ & $\mathrm{X}$ & $\mathrm{X}$ \\
\hline $\begin{array}{c}\text { Cisco Discovery } \\
\text { Protocol }\end{array}$ & $\mathrm{O}$ & $\mathrm{X}$ & $\mathrm{X}$ & $\mathrm{X}$ \\
\hline
\end{tabular}

TABLE IV. AVAILABle FunCtions OF StORAGE/BACKuP

\begin{tabular}{|c|c|c|c|c|}
\hline Function & VMware & Hyper_V & Xen & KVM \\
\hline Boot from SAN & $\mathrm{O}$ & $\mathrm{O}$ & $\Delta$ & $\mathrm{O}$ \\
\hline $\begin{array}{c}\text { Storage I/0 } \\
\text { Control }\end{array}$ & $\mathrm{O}$ & $\mathrm{X}$ & $\mathrm{X}$ & $\mathrm{X}$ \\
\hline $\begin{array}{c}\text { Storage Thin } \\
\text { Provisioning }\end{array}$ & $\mathrm{O}$ & $\mathrm{O}$ & $\Delta$ & $\mathrm{O}$ \\
\hline VM Snapshot & $\mathrm{O}$ & $\mathrm{O}$ & $\mathrm{O}$ & Off line \\
\hline
\end{tabular}

TABLE V. Available FunCtions of MANAGEMENT

\begin{tabular}{|c|c|c|c|c|}
\hline Function & VMware & Hyper_V & Xen & KVM \\
\hline $\begin{array}{c}\text { vCenter Update } \\
\text { Manager }\end{array}$ & $\mathrm{O}$ & $\Delta$ & $\mathrm{X}$ & $\mathrm{X}$ \\
\hline $\begin{array}{c}\text { Management } \\
\text { Console } \\
\text { Expandability }\end{array}$ & $\mathrm{O}$ & $\mathrm{O}$ & $\mathrm{O}$ & $\mathrm{O}$ \\
\hline $\begin{array}{c}\text { Management } \\
\text { Console } \\
\text { Monitoring }\end{array}$ & $\mathrm{O}$ & $\Delta$ & $\mathrm{O}$ & $\mathrm{O}$ \\
\hline Host Profiling & $\mathrm{O}$ & $\mathrm{X}$ & $\mathrm{X}$ & $\mathrm{X}$ \\
\hline
\end{tabular}

Table IV and V show available functions of storage/backup and management. VM snapshot function is for backup and recovery each virtual machine. That function is important because naval combat system is used in battle field.

\section{Performance Evaluations on DDS}

Every node communicates with other nodes through message on DDS environment of naval combat system. In this paper, network performance is evaluated through message response time on DDS environment [9], [10].

In the experiment, Topic size is 2048 bytes and Fragment size is 8 bytes. 5000 topics are transmitted to other virtual machine per one time. Experiment is processed using developed tool can set up topic size, fragment size and transmission times.
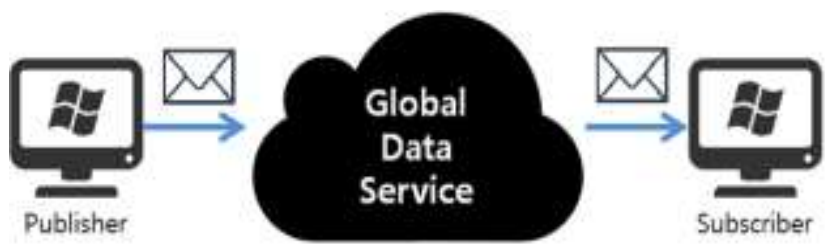

Figure 4. Scenario of Message Transmission Experiment.

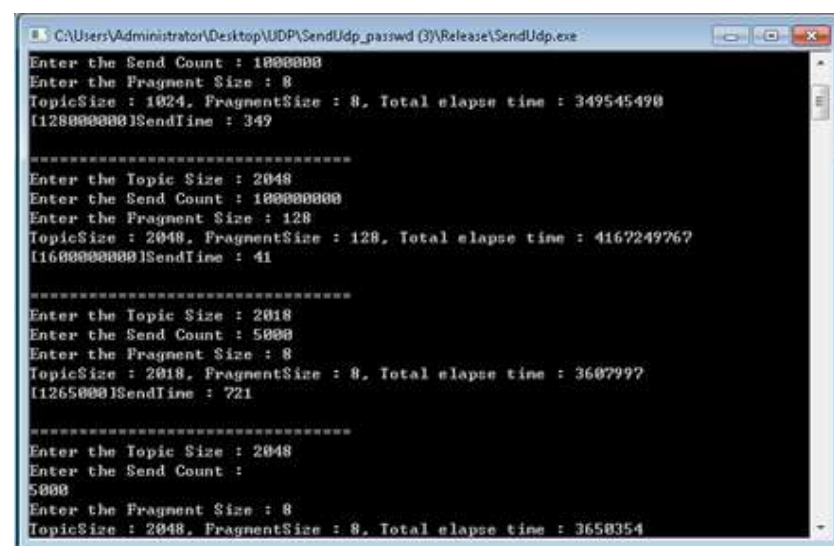

Figure 5. Message Transmission Test Tool.

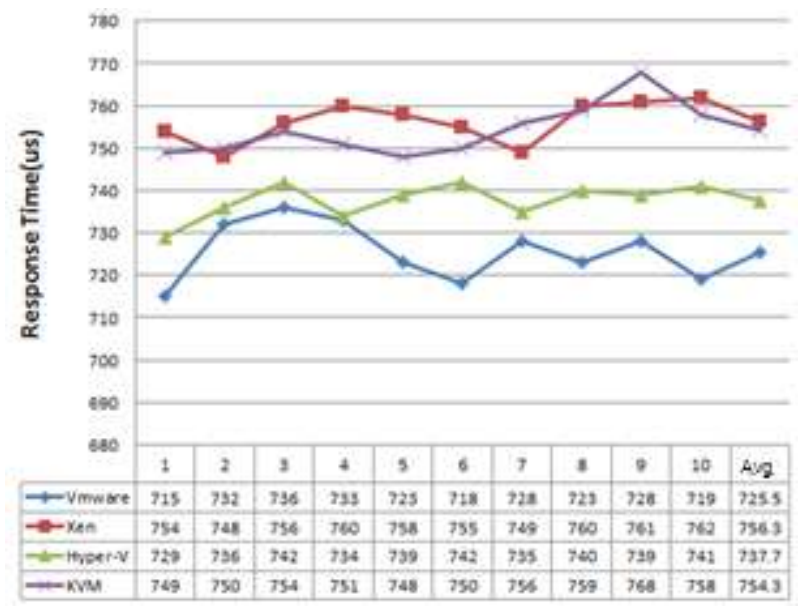

Figure 6. Message Transmission Results.

Average results show that performances are VMware Hyper-V - KVM - Xen. KVM and Xen show similar performance and VMware shows the best performance. However average of message transmission results show 4 kinds of virtualization schemes are enough to requirement of hard real-time message transmission dead line(10ms) for next generation naval combat system.

\section{v. Conclusions and Future Works}

This paper investigates available functions and evaluates performance of message transmission for the next generation naval combat system virtualization environment. In the case of available function, 4 kinds of virtualization scheme show different strength area. Specially, VMware can provide available function more than other virtualization scheme for expandability, flexibility and other kinds of naval combat system characteristic.

Experimental results show that VMware has best performance of message transmission on DDS. In contrast, Xen hypervisor shows worst performance due to the original scheduling method which is credit scheduler. In Xen hypervisor, when virtual machine has overload, credit scheduler have shown performance degradation.

For future work, we will research about fast disaster recovery using high availability(HA) function and Xen hypervisor scheduler to enhance the performance. 


\section{Acknowledgment}

This research was financially supported by National Research Foundation of Korea (NRF) through the Human Resource Training Project for Regional Innovation 2015 (NO. NRF-2015H1C1A1035971), the MSIP(Ministry of Science, ICT and Future Planning), Korea, under the "Creative ICT Convergence Human Resource Development Program" (NO. IITP-2017-H8601-15-1011) support program supervised by the IITP(Institute for Information and communications Technology Promotion) and BK21+ Project in Kumoh National Institute of Technology.

\section{References}

[1] CIO, U.S. Department of the Army, Thin/Zero Client Computing Reference Architecture Ver. 1.0, 1 May 2013.

[2] D.-S. Kim, S. K. Huh "Distributed Control Networks of Naval Combat Systems," Journal of KIICE, Vol. 13, No. 2, pp. 41-47, Dec. 2012.

[3] Jin Yong Im, Dong Seong Kim, Kyung Sub Song and Yoon Suk Choi, "Design and Realization of Distributed Real-time Message Management Scheme for Naval Combat System Development Tool", Journal of Institute fo Control, Robotics and Systems, vol. 22, no. 7, pp. 570-577, July 2016.

[4] Junho Eum, Sangyoon Oh, "Cloud Computing Model to Naval Shipboard Computing System for its High Availability and Optimization", Journal of KIISE : Computing Practices and Letters, vol. 20(4), pp. 219-223, 2014

[5] VMware, "VMware ESXi' ${ }^{\mathrm{TM}} 5.0$ Operations Guide", Technical White Paper, 2011.

[6] Microsoft, "Why Hyper-V? Competitive Advantages of Microsoft Hyper-V Server 2012 over the VMware vSphere Hypervisor", v1.0, January 2013.

[7] The Xen Team, "Xen Users' manual", Xen v2.0 for x86, 2004.

[8] Laura Novich, Dayle Parker, Scott Radvan, Tahlia Richardson, "Red Hat Enterprise Linux 7 Virtualization Deployment and Administration Guide", Revision 2-24, Dec, 2015.

[9] Muhammad Rizal Khaefi, Jin-Yong Im and Dong-Seong Kim, "An Efficient DDS Node Discovery for Naval Combat Systems", IEEE International Conference on Emerging Technologies and Factory Automation (ETFA) 2015, Luxembourg, Sept. pp. 8-11, 2015.

[10] D.-S. Kim, Y.-S. Lee, W.-H. Kwon, "Maximum Allowable Delay Bounds in Networked Control Systems", Control Engineering Practice, Vol. 11, Issue 11, pp. 1301-1313, 2003.
About Author (s):

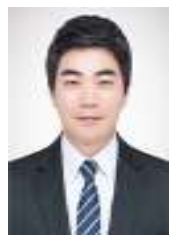

Jin-Yong Im is a Ph.D. student at Department of IT Convergence Engineering, Kumoh National Institute of Technology, Republic of Korea. His research interests are Virtualization Environments and Naval Combat Systems.

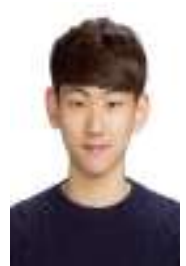

Sung-Hun Kim is a high school student at Cheong Shim International Academy, Republic of Korea. His research interests are Embedded Systems and Software Design.

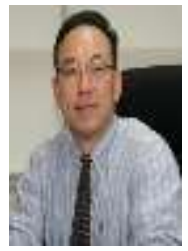

Dong-Seong Kim received his Ph.D. degree in Electrical and Computer Engineering from the Seoul National University, Seoul, Korea, in 2003. From 1994 to 2003, he worked as a full-time researcher in ERC-ACI at Seoul National University, Seoul, Korea. From March 2003 to February 2005, he worked as a postdoctoral researcher at the Wireless Network Laboratory in the School of Electrical and Computer Engineering at Cornell University, NY. He is currently a director of kit Convergence Research Institute and ICT Convergence Research Center supported by Korean government at Kumoh National Institute of Technology. He is IEEE and ACM senior member. His current main research interests are industrial wireless control network, networked embedded system and Fieldbus. 